\title{
Pulmonary haemodynamics during recovery from maximum incremental cycling exercise
}

\author{
Rudolf K.F. Oliveira 1,2,3, Aaron B. Waxman ${ }^{1,2}$, Manyoo Agarwal ${ }^{1,2}$, \\ Roza Badr Eslam ${ }^{1,2,4}$ and David M. Systrom ${ }^{1,2}$
}

Affiliations: ${ }^{1}$ Pulmonary and Critical Care Medicine, Dept of Medicine, Brigham and Women's Hospital and Harvard Medical School, Boston, MA, USA. ${ }^{2}$ Heart and Vascular Center, Brigham and Women's Hospital, Boston, MA, USA. ${ }^{3}$ Division of Respiratory Diseases, Dept of Medicine, Federal University of São Paulo (UNIFESP), São Paulo, Brazil. "Dept of Internal Medicine II, Division of Cardiology, Medical University of Vienna, Vienna, Austria.

Correspondence: David M. Systrom, Pulmonary and Critical Care Medicine, Dept of Medicine, Brigham and Women's Hospital, Clinics 3, 75 Francis Street, Boston, MA 02115, USA. E-mail: dsystromapartners.org

ABSTRACT Assessment of cardiac function during exercise can be technically demanding, making the recovery period a potentially attractive diagnostic window. However, the validity of this approach for exercise pulmonary haemodynamics has not been validated.

The present study, therefore, evaluated directly measured pulmonary haemodynamics during 2-min recovery after maximum invasive cardiopulmonary exercise testing in patients evaluated for unexplained exertional intolerance. Based on peak exercise criteria, patients with exercise pulmonary hypertension $(\mathrm{ePH} ; \mathrm{n}=36)$, exercise pulmonary venous hypertension $(\mathrm{ePVH} ; \mathrm{n}=28)$ and age-matched controls $(\mathrm{n}=31)$ were analysed.

By 2 -min recovery, $83 \%(n=30)$ of $\mathrm{ePH}$ patients had a mean pulmonary artery pressure (mPAP) $<30 \mathrm{mmHg}$ and $96 \%(\mathrm{n}=27)$ of ePVH patients had a pulmonary arterial wedge pressure (PAWP) $<20 \mathrm{mmHg}$. Sensitivity of pulmonary hypertension-related haemodynamic measurements during recovery for $\mathrm{ePH}$ and $\mathrm{ePVH}$ diagnosis was $\leqslant 25 \%$. In $\mathrm{ePVH}$, pulmonary vascular compliance (PVC) returned to its resting value by 1 -min recovery, while in $\mathrm{ePH}$, elevated pulmonary vascular resistance (PVR) and decreased PVC persisted throughout recovery.

In conclusion, we observed that mPAP and PAWP decay quickly during recovery in $\mathrm{ePH}$ and $\mathrm{ePVH}$, compromising the sensitivity of recovery haemodynamic measurements in diagnosing pulmonary hypertension. ePH and ePVH had different PVR and PVC recovery patterns, suggesting differences in the underlying pulmonary hypertension pathophysiology.

@ERSpublications

Pulmonary vascular pressures quickly recover after exercise, but patterns differ between exercise PH and exercise PVH http://ow.ly/ZFGwk

Editorial comment in: Eur Respir J 2016; 48: 18-20.

This article has supplementary material available from erj.ersjournals.com

Received: Jan 052016 | Accepted after revision: March 172016 | First published online: April 282016

Support statement: Rudolf K. F. Oliveira receives funds from the São Paulo Research Foundation (FAPESP) (grant number: 2014/12212-5) and from the Brazilian National Council for Scientific and Technological Development (CNPq) (grant number: 232643/2014-8). Roza Badr Eslam receives funds from the Austrian Science Fund (FWF), Erwin Schroedinger (grant number: J3522-B13). Aaron B. Waxman and David M. Systrom are funded by NIH 2R01HL060234-12A1 and U01HL125215-01. Funding information for this article has been deposited with FundRef.

Conflict of interest: None declared.

Copyright OERS 2016 


\section{Introduction}

Pulmonary hypertension $(\mathrm{PH})$ is currently defined by a mean pulmonary artery pressure (mPAP) $\geqslant 25 \mathrm{mmHg}$ at resting right heart catheterisation [1]. Historically, the diagnosis of $\mathrm{PH}$ with exercise (i.e. normal mPAP at rest but elevated during exercise) was part of the $\mathrm{PH}$ definition [2]. However, the exercise criteria of $\mathrm{PH}$ were abandoned at the 4th World Symposium on PH in 2008 [3]. Since then, however, there is growing evidence that precapillary $\mathrm{PH}$ diagnosed during exercise $(\mathrm{ePH})$ is a clinically and physiologically relevant condition, possibly representing an early stage of resting precapillary $\mathrm{PH}$ [4-10]. In this context, ePH and resting $\mathrm{PH}$ might share pathophysiological mechanisms, such as pulmonary vasoconstriction and vascular remodelling, which affect the pulmonary vascular response to exercise.

In an analogous fashion, post-capillary $\mathrm{PH}$ diagnosed during exercise (exercise pulmonary venous hypertension $(\mathrm{ePVH})$ ), characterised by an exaggerated increase of pulmonary arterial wedge pressure (PAWP) during exercise, is associated with a reduced exercise capacity [11-13], representing an early stage of heart failure preserved ejection fraction (HFpEF). Hence, ePVH and resting HFpEF may have similar $\mathrm{PH}$ mechanisms, such as passive pulmonary venous pressure increase due to impaired left ventricular diastolic reserve [14].

The diagnosis of ePH and ePVH relies on direct measurements of pulmonary haemodynamics during exercise; however, peak exercise haemodynamic measurements can be technically challenging. For instance, marked positive end-expiratory pleural pressure can lead to overestimation of MPAP and PAWP and an inappropriate diagnosis of $\mathrm{PH}$, especially in patients with obesity and chronic obstructive pulmonary disease [15]. Additionally, movement artefact may compromise haemodynamic waveform analysis during intense workload. These technical issues make the recovery period following peak of exercise a potentially attractive domain when respiratory and movement artefacts are less pronounced.

In the current study, we analysed pulmonary haemodynamics during recovery after maximum upright invasive cardiopulmonary exercise testing (CPET) in $\mathrm{ePH}, \mathrm{ePVH}$ and age-matched controls. We sought to evaluate the diagnostic performance of pulmonary haemodynamics measurements during recovery as a surrogate of those obtained during exercise, and to better characterise $\mathrm{ePH}$ and $\mathrm{ePVH}$ recovery patterns. We hypothesised that $\mathrm{ePH}$ and $\mathrm{ePVH}$ haemodynamics would quickly recover, but that their recovery patterns would differ as a reflection of the underlying $\mathrm{PH}$ pathophysiology.

\section{Methods}

\section{Design and study population}

We analysed 442 consecutive patients referred to the Dyspnoea Clinic at Brigham and Women's Hospital (Boston, MA, USA) between December 2012 and December 2014 who underwent an upright symptom-limited invasive CPET on a cycle ergometer as part of their clinically indicated evaluation for unexplained exertional intolerance [16].

Based on peak exercise parameters, subjects were classified as ePH or ePVH according to the following criteria. 1) ePH: peak $\mathrm{mPAP} \geqslant 30 \mathrm{mmHg}$, peak PAWP $<20 \mathrm{mmHg}$ and peak pulmonary vascular resistance $(\mathrm{PVR}) \geqslant 120 \mathrm{dyn} \cdot \mathrm{s} \cdot \mathrm{cm}^{-5}$ [16, 17]; or 2) ePVH: peak PAWP $\geqslant 20 \mathrm{mmHg}[13,17]$. A contemporary age-matched control group was analysed in order to evaluate normal haemodynamic patterns during recovery from peak exercise. Controls were selected based on maximum oxygen uptake $\left(V^{\prime} \mathrm{O}_{2} \max \right) \geqslant 80 \%$ predicted [18], in the absence of the aforementioned abnormal exercise haemodynamic diagnosis.

Exclusion criteria included: 1) submaximal exercise testing: peak respiratory exchange ratio (RER) $<1.0 ; 2)$ pulmonary mechanical limitation to exercise: minute ventilation $\left(V^{\prime} \mathrm{E}\right) /$ maximum voluntary ventilation $(\mathrm{MVV})$ at the anaerobic threshold $(\mathrm{AT}) \geqslant 0.7[18,19]$; 3) resting pulmonary arterial hypertension: rest $\mathrm{mPAP} \geqslant 25 \mathrm{mmHg}$, rest PAWP $\leqslant 15 \mathrm{mmHg}$ and rest PVR $\geqslant 240$ dyn. $\mathrm{s} \cdot \mathrm{cm}^{-5}$ [1]; 4) echocardiographic structural abnormalities: moderate/severe mitral and/or aortic valve disease or left ventricular ejection fraction <0.5; and 5) anaemia: haemoglobin concentration $<10 \mathrm{~g} \cdot \mathrm{dL}^{-1}$. Partners Human Research Committee (Boston, MA, USA) approved this study (protocol \#2011P000272).

\section{Invasive CPET}

Our invasive CPET methods have been described previously $[13,16]$. Briefly, after placement of a pulmonary artery catheter via the internal jugular vein and a radial artery catheter, patients underwent a symptom-limited incremental CPET using an upright cycle ergometer and a breath-by-breath metabolic cart (ULTIMA CPX; Medical Graphics Corporation, St Paul, MN, USA), with simultaneous haemodynamic monitoring (Xper Cardio Physiomonitoring System; Philips, Melborne, FL, USA). All tests were preceded by a 3-min warm-up period of unloaded cycling at $55-65 \mathrm{rpm}$. The work ramp was individually selected $\left(10-25 \mathrm{~W} \cdot \mathrm{min}^{-1}\right)$ according to exertional tolerance history. After achieving symptom-limited maximum exercise, patients underwent a 2-min recovery period consisting of $1 \mathrm{~min}$ of unloaded cycling followed by $1 \mathrm{~min}$ of rest. 
$V^{\prime}$ E, pulmonary gas exchange, heart rate, radial arterial blood pressure, right atrial pressure and PAP were continuously measured. PAWP was measured at rest and at the end of each minute of exercise at the end of a passive exhalation; when respirophasic changes persisted, an electronic average over three respiratory cycles was used [15]. If catheter whip was observed, it was overcome with catheter repositioning and flushing. At rest and during the last $15 \mathrm{~s}$ of each minute of exercise, arterial and mixed venous blood samples were simultaneously collected. Oxygen saturation and haemoglobin concentration were measured and arterial-mixed venous oxygen content $\left(\mathrm{C}(\mathrm{a}-\mathrm{v}) \mathrm{O}_{2}\right)$ were calculated.

Cardiac output $(\mathrm{CO})$ was calculated by the Fick principle using a simultaneously measured $V^{\prime} \mathrm{O}_{2}$. Predicted maximal $\mathrm{CO}$ was calculated from predicted $V^{\prime} \mathrm{O}_{2} \max$ and an assumed maximal $\mathrm{C}(\mathrm{a}-\mathrm{v}) \mathrm{O}_{2}$ difference equivalent to haemoglobin concentration for healthy subjects [20,21]. Total pulmonary vascular resistance (TPR) and PVR were calculated by (mPAP/CO) and (mPAP-PAWP/CO) respectively, and expressed as dyn $\cdot s \cdot \mathrm{cm}^{-5}$. Pulmonary vascular compliance (PVC) was calculated by: stroke volume/systolic minus diastolic PAP. The product of PVR ( $\left.\mathrm{mmHg} \cdot \mathrm{s} \cdot \mathrm{mL}^{-1}\right)$ and PVC $\left(\mathrm{mL} \cdot \mathrm{mmHg}^{-1}\right)$ was calculated and expressed in seconds (RC-time).

\section{Statistical analysis}

Data are presented as mean $\pm \mathrm{SD}$, unless otherwise stated. After determination of equal variance using Levene's test, comparisons among controls, ePVH and ePH were performed using one-way ANOVA or Welch's ANOVA, with Tukey's or Games-Howell post hoc analysis where appropriate. Sub-analysis of ePVH, based on a peak PVR of $120 \mathrm{dyn} \cdot \mathrm{s} \cdot \mathrm{cm}^{-5}$, was performed using the t-test or Mann-Whitney test, where appropriate. Categorical variables were compared using Chi-squared and Fisher's exact tests. Repeated measures ANOVA was used to evaluate variances of haemodynamic variables during different exercise phases. Diagnostic performance of haemodynamic measurements at 1- and 2-min recovery in identifying $\mathrm{ePH}$ and $\mathrm{ePVH}$ were performed using the same cut-off values of mPAP, PAWP and PVR as used for peak exercise diagnostic criteria. $\mathrm{p}<0.05$ was considered significant. The statistical analyses were performed using SPSS software (version 19; IBM Company, Armonk, NY, USA).

\section{Results}

\section{Study population}

Of the 442 invasive CPET reports analysed, 245 had complete 2-min recovery haemodynamics recorded. Based on the aforementioned peak exercise criteria, $36 \mathrm{ePH}$ and $28 \mathrm{ePVH}$ patients were identified and 31 age-matched controls were selected, yielding our study population $(n=95)$. Their baseline characteristics are shown in table 1.

The mean age for the entire population was $62 \pm 10$ years, and $67 \%$ was female. There were no differences regarding sex, weight, haemoglobin concentration or echocardiography measurements among the groups. Diabetes mellitus was more common in $\mathrm{PVH}$, while connective tissue disease and history of pulmonary embolism were more common in $\mathrm{ePH}$. $\mathrm{ePVH}$ and $\mathrm{ePH}$ were more likely to be prescribed $\beta$-adrenergic receptor blockers compared to controls (table 1). None of the studied patients were using phosphodiesterase type- 5 inhibitors or any other specific drugs for pulmonary arterial hypertension at the time of the invasive CPET.

\section{CPET parameters}

ePH and ePVH had lower peak work rate, peak $V^{\prime} \mathrm{O}_{2}$ and $V^{\prime} \mathrm{O}_{2}$ at the AT compared to controls (table 2). There were no differences regarding $V^{\prime} \mathrm{E} / \mathrm{MVV}$ at the AT and at peak exercise. There was a tendency of higher ventilatory equivalent for carbon dioxide $\left(V^{\prime} \mathrm{E} / V^{\prime} \mathrm{CO}_{2}\right.$ slope) in ePVH and ePH compared to controls (table 2).

\section{Haemodynamics}

Resting haemodynamics were significantly different for ePH and ePVH for mPAP, PAWP, TPR, PVR and PVC compared to controls (table 3). Based on our inclusion criteria, peak exercise haemodynamics were different for ePH, ePVH and controls (table 4).

For ePVH, heart rate was significantly lower at peak exercise and throughout recovery compared to ePH and controls (table 4). mPAP remained elevated until 2-min recovery compared to rest and controls (figure 1a), and PAWP remained elevated until 2-min recovery compared to controls and ePH (figure $1 \mathrm{~b}$ ).

For ePH, mPAP also remained elevated until the second minute of recovery compared to rest and controls (figure 1a), and PVR was higher until the second minute of recovery compared to controls (figure $2 \mathrm{a}$ ). Additionally, ePH had persistently reduced PVC throughout recovery compared to ePVH and controls (figure 2b). RC-time was significantly higher at peak exercise in $\mathrm{ePH}$; however, it was not different among the three groups at 1 and 2 min of recovery (table 4 ). 


\begin{tabular}{|c|c|c|c|c|}
\hline & Controls & ePVH & ePH & p-value \\
\hline Subjects & 31 & 28 & 36 & \\
\hline Age years & $59 \pm 9$ & $65 \pm 8$ & $63 \pm 12$ & 0.12 \\
\hline Females & $22(71)$ & $15(54)$ & $27(75)$ & 0.17 \\
\hline $\mathrm{BMI} \mathrm{kg} \cdot \mathrm{m}^{-2}$ & $30 \pm 5$ & $33 \pm 6$ & $32 \pm 6$ & 0.10 \\
\hline Haemoglobin $\mathrm{g} \cdot \mathrm{dL}^{-1}$ & $14.3 \pm 1.5$ & $13.6 \pm 1.9$ & $13.5 \pm 1.7$ & 0.15 \\
\hline \multicolumn{5}{|l|}{ Comorbidities and PH risk factors } \\
\hline Hypertension & $19(61)$ & $18(64)$ & $21(58)$ & 0.11 \\
\hline Diabetes mellitus & $1(3)$ & $12(43)^{*, \pi}$ & $7(19)^{*}$ & $<0.01$ \\
\hline Coronary artery disease & $5(16)$ & $3(11)$ & 1 (3) & 0.14 \\
\hline Connective tissue disease & $3(10)$ & $1(4)$ & $9(25)^{\pi}$ & 0.03 \\
\hline Chronic obstructive pulmonary disease & 0 & 2 (7) & 1 (3) & 0.39 \\
\hline History of pulmonary embolism & 1 (3) & 0 & $4(11)$ & 0.07 \\
\hline \multicolumn{5}{|l|}{ Medications } \\
\hline Diuretics & $10(32)$ & $14(50)^{9}$ & $5(14)$ & $<0.01$ \\
\hline ACE inhibitor or ARB & $8(26)$ & $11(39)$ & $15(42)$ & 0.38 \\
\hline$\beta$-adrenergic receptor blocker & $3(10)$ & $11(39)^{*}$ & $12(33)^{*}$ & 0.02 \\
\hline Calcium channel blocker & $3(10)$ & 9 (32) & $8(22)$ & 0.10 \\
\hline \multicolumn{5}{|l|}{ Echocardiography } \\
\hline Left atrium antero-posterior diameter $\mathrm{mm}$ & $36 \pm 4$ & $37 \pm 6$ & $36 \pm 6$ & 0.73 \\
\hline LVEF \% & $63 \pm 4$ & $63 \pm 5$ & $63 \pm 5$ & 0.99 \\
\hline $\mathrm{TRV}^{\#} \mathrm{~m} \cdot \mathrm{s}^{-2}$ & $2.5 \pm 0.4$ & $2.7 \pm 0.4$ & $2.5 \pm 0.5$ & 0.07 \\
\hline Estimated sPAP mmHg & $27 \pm 6$ & $34 \pm 10$ & $28 \pm 9$ & 0.07 \\
\hline
\end{tabular}

Data are presented as $n$, mean \pm SD or $n(\%)$, unless otherwise stated. ePVH: exercise pulmonary venous hypertension; ePH: exercise pulmonary hypertension; BMI: body mass index; PH: pulmonary hypertension; ACE: angiotensin-converting- enzyme; ARB: angiotensin II receptor antagonist; LVEF: left ventricular ejection fraction; TRV: tricuspid regurgitant jet velocity; sPAP: systolic pulmonary artery pressure. \#: detected in 54 subjects (19 ePH, 13 ePVH and 22 controls); ๆ: $p<0.05$ comparing ePH versus ePVH; *: $p<0.05$ compared with controls.

A sub-analysis of ePVH according to the peak PVR revealed a lower PVC during recovery for ePVH with peak PVR $\geqslant 120$ dyn $\cdot \mathrm{s} \cdot \mathrm{cm}^{-5}$ compared to $\mathrm{ePVH}$ with peak PVR $<120$ dyn $\cdot \mathrm{s} \cdot \mathrm{cm}^{-5}$ both at 1 -min recovery $\left(2.9 \pm 1.7 \mathrm{~mL} \cdot \mathrm{mmHg}^{-1}\right.$ versus $\left.5.0 \pm 1.9 \mathrm{~mL} \cdot \mathrm{mmHg}^{-1}, \mathrm{p}<0.05\right)$ and at 2 -min recovery $\left(3.6 \pm 2.0 \mathrm{~mL} \cdot \mathrm{mmHg}^{-1}\right.$ versus $\left.4.9 \pm 1.7 \mathrm{~mL} \cdot \mathrm{mmHg}^{-1}, \mathrm{p}<0.05\right)$. Additionally, we observed that $\mathrm{ePVH}$ with high peak PVR had decreased peak CO $\left(9.3 \pm 2.2 \mathrm{~L} \cdot \mathrm{min}^{-1}\right.$ versus $\left.12.2 \pm 3.4 \mathrm{~L} \cdot \mathrm{min}^{-1}, \mathrm{p}<0.05\right)$ and reduced peak $V^{\prime} \mathrm{O}_{2}(65 \pm 12 \%$ pred versus $78 \pm 16 \%$ pred, $\mathrm{p}<0.05)$ compared to $\mathrm{ePVH}$ with low peak PVR. The sub-analysis of ePVH according to the peak PVR is presented in the supplementary material (table S1).

\begin{tabular}{|c|c|c|c|c|}
\hline & Controls & ePVH & ePH & p-value \\
\hline Subjects & 31 & 28 & 36 & \\
\hline Peak work rate W & $124 \pm 43$ & $93 \pm 39 *$ & $87 \pm 36 *$ & $<0.01$ \\
\hline Peak V'E L·min ${ }^{-1}$ & $60 \pm 20$ & $45 \pm 19 *$ & $46 \pm 21^{*}$ & 0.02 \\
\hline Peak $V^{\prime} \mathrm{O}_{2} \%$ pred & $95 \pm 10$ & $73 \pm 16^{*}$ & $76 \pm 18 *$ & $<0.01$ \\
\hline Peak $V^{\prime} \mathrm{O}_{2} \mathrm{~mL} \cdot \mathrm{kg}^{-1} \cdot \mathrm{min}^{-1}$ & $19.5 \pm 5.0$ & $13.6 \pm 3.4^{*}$ & $14.0 \pm 4.1 *$ & $<0.01$ \\
\hline$V^{\prime} \mathrm{O}_{2}$ at $\mathrm{AT} \% \mathrm{~V}^{\prime} \mathrm{O}_{2} \max$ pred & $50 \pm 9$ & $39 \pm 8^{*}$ & $41 \pm 8^{*}$ & $<0.01$ \\
\hline Peak systolic BP mmHg & $202 \pm 30$ & $194 \pm 36$ & $203 \pm 28$ & 0.48 \\
\hline Peak diastolic BP $\mathrm{mmHg}$ & $87 \pm 13$ & $83 \pm 19$ & $88 \pm 17$ & 0.38 \\
\hline Peak $V^{\prime}$ E/MVV & $0.65 \pm 0.15$ & $0.66 \pm 0.17$ & $0.72 \pm 0.23$ & 0.40 \\
\hline$V^{\prime} E / M V V$ at $A T$ & $0.27 \pm 0.9$ & $0.28 \pm 0.7$ & $0.31 \pm 0.12$ & 0.26 \\
\hline$V^{\prime} \mathrm{E} / V^{\prime} \mathrm{CO}_{2}$ slope & $31 \pm 5$ & $34 \pm 9$ & $34 \pm 9$ & 0.08 \\
\hline Peak $\mathrm{SaO}_{2} \%$ & $97 \pm 1$ & $97 \pm 1$ & $97 \pm 2$ & 0.28 \\
\hline
\end{tabular}

Data are presented as $\mathrm{n}$ or mean $\pm \mathrm{SD}$, unless otherwise stated. ePVH: exercise pulmonary venous hypertension; ePH: exercise pulmonary hypertension; $V^{\prime} \mathrm{E}$ : minute ventilation; $V^{\prime} \mathrm{O}_{2}$ : oxygen uptake; $V^{\prime} \mathrm{O}_{2}$ max: maximal oxygen uptake; AT: anaerobic threshold; BP: blood pressure; MVV: maximum voluntary ventilation; $V^{\prime} \mathrm{CO}_{2}$ : carbon dioxide production; $\mathrm{SaO}_{2}$ : arterial oxygen saturation. *: $\mathrm{p}<0.05$ compared with controls. 
TABLE 3 Resting haemodynamics

\begin{tabular}{|c|c|c|c|c|}
\hline & Controls & ePVH & ePH & p-value \\
\hline Subjects & 31 & 28 & 36 & \\
\hline Heart rate bpm & $75 \pm 10$ & $73 \pm 13$ & $77 \pm 15$ & 0.55 \\
\hline RAP $\mathrm{mmHg}$ & $4 \pm 2$ & $5 \pm 3$ & $5 \pm 3$ & 0.06 \\
\hline mPAP mmHg & $14 \pm 3$ & $19 \pm 5^{*}$ & $19 \pm 4^{*}$ & $<0.01$ \\
\hline PAWP mmHg & $6 \pm 3$ & $9 \pm 3^{*}$ & $9 \pm 3 *$ & $<0.01$ \\
\hline PAWP-RAPmmHg & $3 \pm 2$ & $4 \pm 2^{*}$ & $4 \pm 2 *$ & $<0.01$ \\
\hline mPAP-PAWP $\mathrm{mmHg}$ & $8 \pm 2$ & $9 \pm 3$ & $10 \pm 3^{*}$ & $<0.01$ \\
\hline $\mathrm{CO} L \cdot \min ^{-1}$ & $4.8 \pm 1.5$ & $4.8 \pm 1.3$ & $4.3 \pm 1.0$ & 0.16 \\
\hline $\mathrm{Cl} \mathrm{L} \cdot \mathrm{min}^{-1} \cdot \mathrm{m}^{-2}$ & $2.5 \pm 0.6$ & $2.4 \pm 0.7$ & $2.2 \pm 0.5$ & 0.07 \\
\hline $\mathrm{SV} \mathrm{mL}$ & $66 \pm 25$ & $67 \pm 21$ & $58 \pm 16$ & 0.14 \\
\hline TPR dyn $\cdot s \cdot \mathrm{cm}^{-5}$ & $248 \pm 96$ & $330 \pm 124^{*}$ & $360 \pm 95^{*}$ & $<0.01$ \\
\hline PVR dyn $\cdot s \cdot \mathrm{cm}^{-5}$ & $134 \pm 49$ & $168 \pm 86$ & $185 \pm 62^{*}$ & $<0.01$ \\
\hline PVC $\mathrm{mL} \cdot \mathrm{mmHg}^{-1}$ & $6.4 \pm 2.5$ & $4.8 \pm 2.1 *$ & $4.5 \pm 1.6^{*}$ & $<0.01$ \\
\hline RC-time s & $0.60 \pm 0.21$ & $0.53 \pm 0.18$ & $0.59 \pm 0.16$ & 0.29 \\
\hline
\end{tabular}

Data are presented as $\mathrm{n}$ or mean $\pm \mathrm{SD}$, unless otherwise stated. ePVH: exercise pulmonary venous hypertension; ePH: exercise pulmonary hypertension; RAP: right atrial pressure; mPAP: mean pulmonary artery pressure; PAWP: pulmonary arterial wedge pressure; CO: cardiac output; $\mathrm{Cl}$ : cardiac index; SV: stroke volume; TPR: total pulmonary vascular resistance; PVR: pulmonary vascular resistance; PVC: pulmonary vascular compliance. * $\mathrm{p}<0.05$ compared with controls.

\section{Diagnostic performance of recovery haemodynamics}

Among ePH, 75\% (27 out of 36) of patients had $\mathrm{mPAP}<30 \mathrm{mmHg}$ at 1 -min recovery (figure $3 \mathrm{a}$ ), and $83 \%$ (30 out of 36 ) at 2-min recovery (figure $3 \mathrm{~b}$ ). Among ePVH, 86\% (24 out of 28) of patients had PAWP $<20 \mathrm{mmHg}$ at 1 -min recovery (figure $3 \mathrm{c}$ ), and $96 \%$ (27 out of 28 ) at 2-min recovery (figure $3 \mathrm{~d}$ ).

Sensitivity and specificity of $\mathrm{PH}$-related haemodynamic measurements at 1- and 2-min recovery in identifying ePH and ePVH are presented in table 5.

\section{Discussion}

In the present study, we found that mPAP and PAWP decay quickly within 1-2 min after peak exercise in $\mathrm{ePH}$ and $\mathrm{ePVH}$, compromising the sensitivity of recovery haemodynamic measurements in diagnosing

TABLE 4 Haemodynamics at peak exercise and recovery

\begin{tabular}{|c|c|c|c|c|c|c|c|c|c|}
\hline & \multicolumn{3}{|c|}{ Controls" } & \multicolumn{3}{|c|}{ ePVH" } & \multicolumn{3}{|c|}{$\mathrm{ePH}^{+}$} \\
\hline Heart rate bpm & $140 \pm 20$ & $125 \pm 18$ & $112 \pm 19$ & $113 \pm 23^{*} \S$ & $102 \pm 20^{*}, \S$ & $90 \pm 18^{* \S \S}$ & $128 \pm 23$ & $116 \pm 20$ & $102 \pm 20$ \\
\hline RAP $\mathrm{mmHg}$ & $7 \pm 3$ & $4 \pm 3$ & $3 \pm 2$ & $12 \pm 5^{*, \S}$ & $6 \pm 2 *$ & $5 \pm 2 *$ & $7 \pm 4$ & $5 \pm 3$ & $5 \pm 2 *$ \\
\hline mPAP mmHg & $27 \pm 6$ & $19 \pm 3$ & $17 \pm 3$ & $40 \pm 9 *$ & $28 \pm 8^{*}$ & $24 \pm 7 *$ & $36 \pm 6^{*}$ & $26 \pm 7^{*}$ & $23 \pm 6^{*}$ \\
\hline $\begin{array}{l}\text { mPAP minus PAWP } \\
\mathrm{mmHg}\end{array}$ & $15 \pm 4$ & $12 \pm 4$ & $10 \pm 3$ & $15 \pm 8$ & $14 \pm 7$ & $12 \pm 5$ & $24 \pm 6^{*, \S}$ & $16 \pm 5^{*}$ & $14 \pm 5 *$ \\
\hline $\mathrm{CO} L \cdot \mathrm{min}^{-1}$ & $12.8 \pm 2.8$ & $10.1 \pm 2.7$ & $8.2 \pm 2.3$ & $11.1 \pm 3.2$ & $9.8 \pm 2.6$ & $8.2 \pm 3.0$ & $10.6 \pm 2.1^{*}$ & $8.8 \pm 2.2$ & $7.5 \pm 2.6$ \\
\hline Peak CO \% pred & $106 \pm 15$ & & & $88 \pm 23 *$ & & & $93 \pm 20 *$ & & \\
\hline $\mathrm{SV} \mathrm{mL}$ & $93 \pm 22$ & $83 \pm 25$ & $77 \pm 27$ & $98 \pm 22$ & $98 \pm 24^{*}$ & $92 \pm 27$ & $84 \pm 14^{\S}$ & $77 \pm 18^{\S}$ & $74 \pm 21^{\S}$ \\
\hline
\end{tabular}

Data are presented as mean \pm SD. ePVH: exercise pulmonary venous hypertension; ePH: exercise pulmonary hypertension; RAP: right atrial pressure; mPAP: mean pulmonary artery pressure; PAWP: pulmonary arterial wedge pressure; CO: cardiac output; SV: stroke volume; TPR: total pulmonary vascular resistance; PVR: pulmonary vascular resistance; PVC: pulmonary vascular compliance. ${ }^{\#}: n=31 ;{ }^{~}: n=28 ;{ }^{+}: n=36$. *: $p<0.05$ compared with controls; ${ }^{\S}$ : $p<0.05$ comparing ePH versus ePVH. 

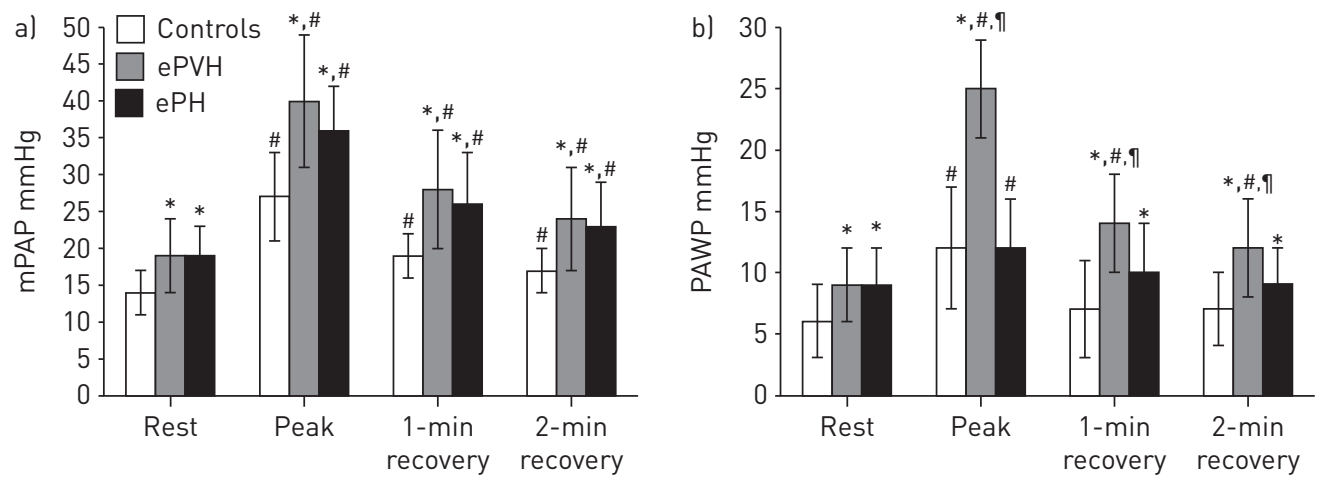

FIGURE 1 Mean pulmonary artery pressure (mPAP) and pulmonary arterial wedge pressure (PAWP) at rest, peak exercise and recovery. ePVH: exercise pulmonary venous hypertension; ePH: exercise pulmonary hypertension. *: $p<0.05$ compared to controls; ${ }^{\#}$ : $p<0.05$ compared to rest; ${ }^{9}$ : $p<0.05$ comparing ePH versus ePVH.

PH. Additionally, ePH and ePVH had different PVR and PVC recovery patterns, suggesting differences in the underlying $\mathrm{PH}$ pathophysiology.

To our knowledge, this is the first study to comprehensively characterise pulmonary haemodynamic patterns following maximum incremental exercise in $\mathrm{ePH}$ and $\mathrm{ePVH}$. Two previous studies have described mPAP and PAWP during recovery from exercise [12, 22]. Similar to the current study, BorLAug et al. [12] described a return of PAWP to its baseline value at 1-min recovery in ePVH. Argiento et al. [22] estimated pulmonary haemodynamics by transthoracic echocardiography in normal subjects at 5 -min recovery and found a rapid return of estimated pulmonary pressures to resting baseline.

\section{Sensitivity and specificity of haemodynamic measurements during recovery}

We observed sensitivity $\leqslant 25 \%$ for PH-related haemodynamic measurements following peak exercise in diagnosing $\mathrm{ePH}$ and $\mathrm{ePVH}$ (table 5). Our results confirm previous noninvasive observations [22] and provide further invasive data to support the notion that $\mathrm{PH}$-related measurements during recovery from exercise are not sufficiently sensitive to exclude $\mathrm{PH}$, even in early phases of recovery. This observation is of major importance not only for invasive haemodynamic measurements, but likely also for noninvasive techniques such as exercise echocardiography and exercise cardiac magnetic resonance.

Exercise echocardiography is commonly used to access the dynamic pulmonary vascular response to exercise $[23,24]$. However, similar to invasive CPET, exercise echocardiography is technically demanding, leading some centres to perform echocardiographic measurements during recovery from peak exercise, given the lack of specific $\mathrm{PH}$-related recommendations in current guidelines [25, 26]. With respect to gated cardiac magnetic resonance-derived haemodynamic measurements, the technical challenge imposed by the acquisition of images suitable for analysis during high-intensity exercise is a major limitation [27]. Additionally, exercising within the narrow diameter of the magnetic resonance imaging bore can be an issue in some cases, making the acquisition of images during recovery more tempting. However, our findings suggest that $\mathrm{PH}$-related haemodynamic measurements acquired solely during recovery miss the
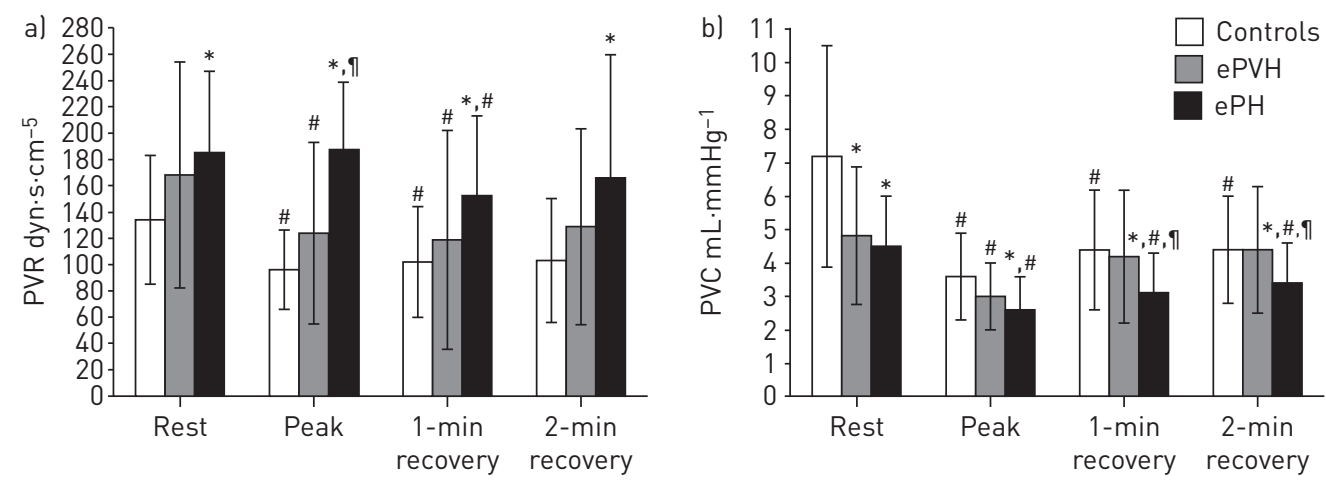

FIGURE 2 Pulmonary vascular resistance (PVR) and pulmonary vascular compliance (PVC) at rest, peak exercise and recovery. ePVH: exercise pulmonary venous hypertension; ePH: exercise pulmonary hypertension. *: $p<0.05$ compared to controls; ${ }^{\#}$ : $p<0.05$ compared to rest; ${ }^{\uparrow}: p<0.05$ comparing ePH versus ePVH. 

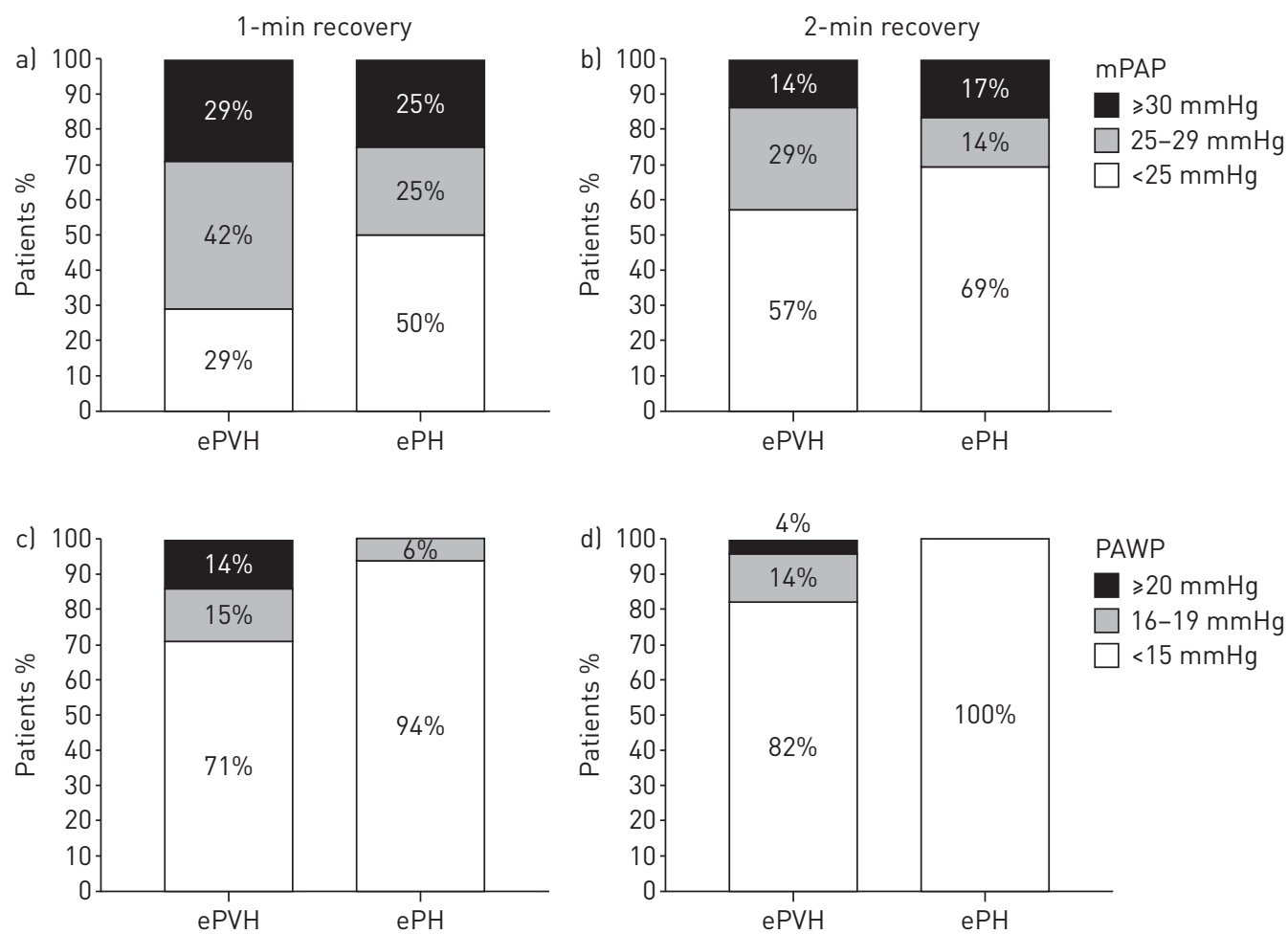

FIGURE 3 Percentage of patients with abnormal a, b) mean pulmonary artery pressure (mPAP) and $c, d$ ) pulmonary arterial wedge pressure (PAWP) during a, c) 1-min recovery and b, d) 2-min recovery. ePVH: exercise pulmonary venous hypertension; ePH: exercise pulmonary hypertension.

majority of ePH and ePVH diagnoses and, therefore, should not be used as a substitute of peak exercise measurements to exclude the presence of ePH and $\mathrm{ePVH}$.

ePH versus ePVH haemodynamic recovery patterns

PVR and PVC recovery patterns were different for ePH and ePVH. PVR remained elevated and PVC remained low in ePH throughout recovery compared to ePVH (figure 2), suggesting differences in the underlying PH pathophysiology.

The pulmonary circulation is influenced by both passive and active factors at rest and during exercise. Passive factors include increases in transmural pressure driven by input (PAP) and outflow pressures (PAWP) that assist in ventilation and perfusion matching, especially in the upright position [28]. Active factors include nitric oxide (NO)-mediated mechanisms, regional alveolar hypoxia and sympathetic nervous system stimulation, which dynamically regulate vasoconstriction and vasodilation, further affecting PVR, recruitment and distension during exercise [29-31]. We observed that ePH PVR elevation persisted

TABLE 5 Sensitivity and specificity of pulmonary hypertension-related haemodynamic measurements during recovery

1-min recovery

2-min recovery

ePH

Sensitivity

Specificity

25

17

ePVH

Sensitivity

Specificity

Data are presented as \%. ePH: exercise pulmonary hypertension; ePVH: exercise pulmonary venous hypertension. Diagnostic performance of recovery haemodynamic measurements in identifying ePH and ePVH were performed using the same cut-off values of mean pulmonary artery pressure, pulmonary arterial wedge pressure and pulmonary vascular resistance used for peak exercise diagnostic criteria (see Methods). 
during recovery (figure 2a), differing from controls and ePVH, and suggesting underlying dynamic pulmonary artery vasoconstriction and/or pulmonary vascular structural remodelling.

PVC represents an early marker of pulmonary vascular remodelling, reflecting the ability of the pulmonary vasculature to distend during systole and recoil during diastole [32]. Therefore, persistently low PVC may indicate intrinsic changes of vessel wall function/structure (stiffness) that can ultimately impact right ventricular performance, as is the case for resting precapillary $\mathrm{PH}$ [33]. In our study, low PVC throughout recovery provides evidence of pathological pulmonary vascular stiffness in ePH. Conversely, in ePVH, PVC returned to its baseline resting value by 1 -min recovery (figure $2 \mathrm{~b}$ ), indicating that $\mathrm{PVH}$ mechanisms are likely to be largely passive (i.e. passive increased transmural pressure due to increased PAWP). Therefore, as PAWP rapidly returns to its baseline value during recovery, PVC is quickly restored. Along these lines, we observed that stroke volume did not decay as fast as PAWP during recovery in ePVH (table 4), suggesting that their high filling pressures are not mandatory in order to maintain forward flow and consequently that ePVH might tolerate some degree of preload reduction without compromising systemic perfusion.

Interestingly, the sub-analysis of ePVH according to peak PVR revealed a blunted PVC recovery in patients with a peak PVR $\geqslant 120$ dyn $\cdot \mathrm{s} \cdot \mathrm{cm}^{-5}$ despite the same pattern of PAWP recovery in both subgroups (table S1), suggesting that ePVH PVC changes are not strictly related to PAWP changes as previously thought [34]. Additionally, we observed that PVC recovery pattern was also not solely explained by heart rate, since both PVC and heart rate were reduced in ePVH with a peak PVR $\geqslant 120$ dyn $\cdot \mathrm{s} \cdot \mathrm{cm}^{-5}$ (table S1). These observations possibly reflect a subgroup of $\mathrm{ePVH}$, in which a sustained increased intravascular pressure led to changes in vascular wall structure [35] and subsequent decrease in pulmonary vascular compliance, as a marker of early pulmonary vascular remodelling and disease severity. In this context, ePVH with peak PVR $\geqslant 120$ dyn $\cdot \mathrm{s} \cdot \mathrm{cm}^{-5}$ also had lower $\mathrm{CO}$ and lower peak $V^{\prime} \mathrm{O}_{2}$ compared to ePVH with peak PVR $<120$ dyn $\cdot \mathrm{s} \cdot \mathrm{cm}^{-5}$ (table S1), suggesting that dynamic increases in right ventricle afterload (PVR and PVC) are physiologically and clinically relevant.

We observed that $\mathrm{ePH}$ failed to increase RC-time during recovery compared to ePVH and controls (table 4) due to equal contributions from abnormal PVR and PVC recovery patterns. The observed RC-time pattern is analogous to the dynamic changes in RC-time described for chronic thromboembolic PH [36], and suggests that an early pulmonary vasculopathy (i.e. $\mathrm{ePH}$ ) has its origins in concordant abnormalities of resistance and compliance. As a result, pulmonary vascular bed dilatation and recruitment during exercise is impaired, subsequently compromising right ventricular function and exercise capacity.

Our ePH findings are in accordance with previously published noninvasive data that demonstrated evidence of pulmonary vascular stiffness by resting cardiac magnetic resonance in ePH [37]. SANZ et al. [37] suggested that, in addition to increases in transmural pressure, changes in intrinsic elastic properties of the pulmonary circulation play a major role in determining pulmonary vascular stiffness and its association with $\mathrm{PH}$ severity. Hence, our findings provide additional direct evidence that ePH represents an early and mild stage of resting $\mathrm{PH}$, possibly presenting similar mechanisms of pulmonary vascular remodelling such as pulmonary vascular wall thickening, smooth muscle cell proliferation and collagen and extracellular matrix deposition.

Heart rate at peak exercise was significantly lower in ePVH (table 4). However, this is unlikely to be solely related to $\beta$-adrenergic blockade, because $\beta$-blocker usage frequency was not different between ePH and ePVH. One possible explanation for this finding might be the presence of chronic sympathetic overstimulation and downregulation of $\beta$-adrenergic receptors, resulting in chronotropic incompetence, which is commonly observed in chronic heart failure. The rate of heart rate recovery was not different among groups (data not shown), which differs from prior reports in established $\mathrm{PH}$ [38] and heart failure [39]. However, our study evaluated only $\mathrm{ePH}$ and $\mathrm{ePVH}$, in which delayed heart rate recovery might not be present due to the early/mild stage of disease.

Finally, the rapid decrease in pulmonary pressures during recovery emphasises the ephemeral nature of haemodynamic derangement in $\mathrm{ePH}$ and $\mathrm{ePVH}$ and highlights the potential role of specific therapies targeting the exercise phase. This approach has recently been reported for HFpEF using acutely infused sodium nitrite, which is converted to NO during exercise boosted by hypoxia and acidosis [40]. By targeting active factors of the pulmonary circulation (NO-mediated mechanisms), BorlaUg et al. [40] demonstrated the beneficial effects of nitrite on exercise haemodynamics by the reduction in PAWP and PAP during exercise, and improvements in exercise CO reserve, with less effect on resting haemodynamics. However, whether or not this approach might also be applicable to $\mathrm{ePH}$ or ePVH with evidence of pulmonary vascular remodelling (i.e. elevated PVR and reduced PVC) needs further investigation.

\section{Limitations}

Studied patients were derived from a single tertiary dyspnoea centre, and likely represent an early/mild stage of disease. Therefore, they may not represent an overall community-based population and the generalisation 
of our findings to other $\mathrm{PH}$ populations should be done with caution. The control group was symptomatic and, therefore, may not represent a completely normal population. However, controls had normal exercise capacity and exercise haemodynamics. The sample studied included overweight patients, whose exercise haemodynamics measurements may show some degree of inaccuracy. However, a sub-analysis of patients with a body mass index $>35 \mathrm{~kg} \cdot \mathrm{m}^{-2}$ (table S2) revealed similar pulmonary haemodynamics to the entire study population, demonstrating that elevated body mass index did not affect $\mathrm{ePH}$ and ePVH recovery patterns.

For the ePH group, we used a $\mathrm{mPAP} \geqslant 30 \mathrm{mmHg}$ associated with a PVR $\geqslant 120 \mathrm{dyn} \cdot \mathrm{s} \cdot \mathrm{cm}^{-5}$, in the absence of elevated filling pressures during exercise, based on a prior report using a similar maximum incremental cycling protocol [17]. This ePH definition essentially describes the same exercise haemodynamic phenotype as the approach that uses a peak TPR $>240$ dyn $\cdot \mathrm{s} \cdot \mathrm{cm}^{-5}$ after a PAWP $>20 \mathrm{mmHg}$ is first excluded [9]. In our study, the majority of the ePH population (22 out of 36) met both criteria (PVR $\geqslant 120 \mathrm{dyn} \cdot \mathrm{s} \cdot \mathrm{cm}^{-5}$ and TPR $>240 \mathrm{dyn} \cdot \mathrm{s} \cdot \mathrm{cm}^{-5}$ ). Furthermore, our ePH group represents a population with clinically relevant pulmonary vascular dysfunction, because the presence of ePH clearly impacted their exercise capacity (as measured by peak $V^{\prime} \mathrm{O}_{2}$ ) compared to controls (table 2). For ePVH, we used a peak PAWP $\geqslant 20 \mathrm{mmHg}$. We acknowledge that there remains no consensus on the optimal cut-off value to categorise elevated filling pressures during exercise; however, the $20 \mathrm{mmHg}$ threshold is in accordance with previous studies of post-capillary $\mathrm{PH}$ during exercise $[4,9,12,13]$, and in a similar manner to ePH, the presence of ePVH was associated with a reduced exercise capacity (tables 2 and S1).

Elevation of intrathoracic pressures during exercise might influence exercise haemodynamics; however, this influence is expected to be of equal magnitude on right atrial pressure and PAWP [15]. Using $V^{\prime} \mathrm{E}$ as a surrogate of intrathoracic pressure (and pleural pressure in our subjects without parenchymal lung disease) we found that intrathoracic pressures did not play a major role on PAWP. The increased peak PAWP and peak PAWP minus RAP in ePVH (table 4) occurred at the same $V^{\prime} \mathrm{E}$ (and presumably same pleural pressure) in the ePH group (table 2). This suggests that ePVH PAWP changes during exercise are related to intrinsic changes in lusitropy rather than changes in pleural pressure itself. Additionally, the low filling pressures during exercise in controls (table 4) were observed at elevated $V^{\prime} \mathrm{E}$ (and presumably elevated pleural pressure) compared to $\mathrm{ePH}$ and $\mathrm{ePVH}$ (table 2), reinforcing the notion that intrathoracic pressures were not the main forces influencing PAWP patterns in ePVH.

For patient's safety, our clinical exercise protocol required $1 \mathrm{~min}$ of freewheeling during recovery to prevent systemic hypotension. The freewheeling hypothetically could have masked differences in recovery; however, all of our key findings were already observed at 1-min recovery despite the freewheeling stage. Another limitation is the relatively small sample size of ePVH subgroups, which might decrease study power with regard to the comparison of ePVH with and without elevated peak PVR. Finally, this was an observational study and, therefore, we are not able to comment on data reproducibility and further (interventional) studies will be necessary to determine the exact mechanisms behind the different ePH and ePVH recovery patterns and their clinical relevance.

\section{Conclusions}

Our study demonstrated that mPAP and PAWP decline quickly during recovery from peak exercise in ePH and $\mathrm{ePVH}$, resulting in a low sensitivity of $\mathrm{PH}$-related haemodynamic measurements during recovery in diagnosing $\mathrm{PH}$. We also observed that PVR and PVC recovery patterns differ between $\mathrm{PPH}$ and $\mathrm{ePVH}$, suggesting differences in the underlying PH pathophysiology. The high PVR and low PVC observed throughout recovery in $\mathrm{ePH}$ suggest that fixed pulmonary vascular remodelling and/or sustained pulmonary vascular dysfunction underlie the abnormal ePH pulmonary haemodynamic response to exercise. We speculate that for similar reasons, ePVH with a high peak PVR exhibits analogous pulmonary haemodynamic recovery pattern to that observed for $\mathrm{ePH}$.

\section{Acknowledgements}

We thank David Yang, Julie A. Tracy and Abbey L. Karin from the Heart \& Vascular Centre (Brigham and Women's Hospital, Harvard Medical School, Boston, MA, USA) for their technical expertise.

\section{References}

1 Galiè N, Humbert M, Vachiery J-L, et al. 2015 ESC/ERS Guidelines for the diagnosis and treatment of pulmonary hypertension. Eur Respir J 2015; 46: 903-975.

2 Rich S, Dantzker DR, Ayres SM, et al. Primary pulmonary hypertension. A national prospective study. Ann Intern Med 1987; 107: 216-223.

3 Badesch DB, Champion HC, Sanchez MAG, et al. Diagnosis and assessment of pulmonary arterial hypertension. J Am Coll Cardiol 2009; 54: Suppl., S55-S66.

4 Tolle JJ, Waxman AB, Van Horn TL, et al. Exercise-induced pulmonary arterial hypertension. Circulation 2008; 118: 2183-2189. 
5 Steen V, Chou M, Shanmugam V, et al. Exercise-induced pulmonary arterial hypertension in patients with systemic sclerosis. Chest 2008; 134: 146-151.

6 Condliffe R, Kiely DG, Peacock AJ, et al. Connective tissue disease-associated pulmonary arterial hypertension in the modern treatment era. Am J Respir Crit Care Med 2009; 179: 151-157.

7 Saggar R, Khanna D, Furst DE, et al. Exercise-induced pulmonary hypertension associated with systemic sclerosis: four distinct entities. Arthritis Rheum 2010; 62: 3741-3750.

8 Lewis GD, Bossone E, Naeije R, et al. Pulmonary vascular hemodynamic response to exercise in cardiopulmonary diseases. Circulation 2013; 128: 1470-1479.

9 Herve P, Lau EM, Sitbon O, et al. Criteria for diagnosis of exercise pulmonary hypertension. Eur Respir J 2015; 46 : $728-737$.

10 Naeije R, Vonk Noordegraaf A, Kovacs G. Exercise-induced pulmonary hypertension: at last! Eur Respir J 2015; 46: 583-586.

11 Kitzman DW, Higginbotham MB, Cobb FR, et al. Exercise intolerance in patients with heart failure and preserved left ventricular systolic function: failure of the Frank-Starling mechanism. J Am Coll Cardiol 1991; 17: 1065-1072.

12 Borlaug BA, Nishimura RA, Sorajja P, et al. Exercise hemodynamics enhance diagnosis of early heart failure with preserved ejection fraction. Circ Heart Fail 2010; 3: 588-595.

13 Santos M, Opotowsky AR, Shah AM, et al. Central cardiac limit to aerobic capacity in patients with exertional pulmonary venous hypertension: implications for heart failure with preserved ejection fraction. Circ Heart Fail 2015; 8: 278-285.

14 Westermann D, Kasner M, Steendijk P, et al. Role of left ventricular stiffness in heart failure with normal ejection fraction. Circulation 2008; 117: 2051-2060.

15 Boerrigter $\mathrm{BG}$, Waxman $\mathrm{AB}$, Westerhof $\mathrm{N}$, et al. Measuring central pulmonary pressures during exercise in COPD: how to cope with respiratory effects. Eur Respir J 2014; 43: 1316-1325.

16 Maron BA, Cockrill BA, Waxman AB, et al. The invasive cardiopulmonary exercise test. Circulation 2013; 127: $1157-1164$.

17 Groves BM, Reeves JT, Sutton JR, et al. Operation Everest II: elevated high-altitude pulmonary resistance unresponsive to oxygen. J Appl Physiol 1987; 63: 521-530.

18 Hansen JE, Sue DY, Wasserman K. Predicted values for clinical exercise testing. Am Rev Respir Dis 1984; 129: Suppl., S49-S55.

19 Medoff BD, Oelberg DA, Kanarek DJ, et al. Breathing reserve at the lactate threshold to differentiate a pulmonary mechanical from cardiovascular limit to exercise. Chest 1998; 113: 913-918.

20 Wasserman K, Hansen JE, Sue DY, et al. Principles of Exercise Testing and Interpretation. 4th Edn. Philadelphia, Lippincott Williams \& Wilkins, 2005.

21 Beck KC, Randolph LN, Bailey KR, et al. Relationship between cardiac output and oxygen consumption during upright cycle exercise in healthy humans. J Appl Physiol 2006; 101: 1474-1480.

22 Argiento $\mathrm{P}$, Chesler N, Mulè M, et al. Exercise stress echocardiography for the study of the pulmonary circulation. Eur Respir J 2010; 35: 1273-1278.

23 Grünig E, Janssen B, Mereles D, et al. Abnormal pulmonary artery pressure response in asymptomatic carriers of primary pulmonary hypertension gene. Circulation 2000; 102: 1145-1150.

24 D'Alto M, Ghio S, D'Andrea A, et al. Inappropriate exercise-induced increase in pulmonary artery pressure in patients with systemic sclerosis. Heart 2011; 97: 112-117.

25 Pellikka PA, Nagueh SF, Elhendy AA, et al. American Society of Echocardiography recommendations for performance, interpretation, and application of stress echocardiography. J Am Soc Echocardiogr 2007; 20: $1021-1041$.

26 Sicari R, Nihoyannopoulos P, Evangelista A, et al. Stress echocardiography expert consensus statement: European Association of Echocardiography (EAE) (a registered branch of the ESC). Eur J Echocardiogr 2008; 9: 415-437.

27 La Gerche A, Claessen G, Van de Bruaene A, et al. Cardiac MRI: a new gold standard for ventricular volume quantification during high-intensity exercise. Circ Cardiovasc Imaging 2013; 6: 329-338.

28 Reeves JT, Moon RE, Grover RF, et al. Increased wedge pressure facilitates decreased lung vascular resistance during upright exercise. Chest 1988; 93: Suppl., 97S-99S.

29 Reeves JT, Linehan JH, Stenmark KR. Distensibility of the normal human lung circulation during exercise. Am J Physiol Lung Cell Mol Physiol 2005; 288: L419-L425.

30 Kane DW, Tesauro T, Koizumi T, et al. Exercise-induced pulmonary vasoconstriction during combined blockade of nitric oxide synthase and beta adrenergic receptors. J Clin Invest 1994; 93: 677-683.

31 Kadowitz PJ, Hyman AL. Effect of sympathetic nerve stimulation on pulmonary vascular resistance in the dog. Circ Res 1973; 32: 221-227.

32 Linehan JH, Dawson CA, Rickaby DA, et al. Pulmonary vascular compliance and viscoelasticity. J Appl Physiol 1986; 61: 1802-1814

33 Lankhaar JW, Westerhof N, Faes TJ, et al. Quantification of right ventricular afterload in patients with and without pulmonary hypertension. Am J Physiol Heart Circ Physiol 2006; 291: H1731-H1737.

34 Tedford RJ, Hassoun PM, Mathai SC, et al. Pulmonary capillary wedge pressure augments right ventricular pulsatile loading. Circulation 2012; 125: 289-297.

35 Breitling S, Ravindran K, Goldenberg NM, et al. The pathophysiology of pulmonary hypertension in left heart disease. Am J Physiol Lung Cell Mol Physiol 2015; 309: L924-L941.

36 Claessen G, La Gerche A, Dymarkowski S, et al. Pulmonary vascular and right ventricular reserve in patients with normalized resting hemodynamics after pulmonary endarterectomy. J Am Heart Assoc 2015; 4: e001602.

37 Sanz J, Kariisa M, Dellegrottaglie S, et al. Evaluation of pulmonary artery stiffness in pulmonary hypertension with cardiac magnetic resonance. JACC Cardiovasc Imaging 2009; 2: 286-295.

38 Ramos RP, Arakaki JSO, Barbosa P, et al. Heart rate recovery in pulmonary arterial hypertension: relationship with exercise capacity and prognosis. Am Heart J 2012; 163: 580-588.

39 Bilsel T, Terzi S, Akbulut $\mathrm{T}$, et al. Abnormal heart rate recovery immediately after cardiopulmonary exercise testing in heart failure patients. Int Heart J 2006; 47: 431-440.

40 Borlaug BA, Koepp KE, Melenovsky V. Sodium nitrite improves exercise hemodynamics and ventricular performance in heart failure with preserved ejection fraction. J Am Coll Cardiol 2015; 66: 1672-1682. 